\title{
Dostoevsky and Epilepsy: An Attempt to Look Through the Frame
}

\author{
Andrea O. Rossetti ${ }^{\mathrm{a}}$, Julien Bogousslavsky ${ }^{\mathrm{b}}$ \\ aEpilepsy Unit, Department of Neurology, Brigham and Women's Hospital, \\ Harvard Medical School, Boston, Mass., USA; 'bervice de Neurologie, \\ Centre Hospitalier Universitaire Vaudois, Lausanne, Switzerland
}

\begin{abstract}
Fyodor Mihailovich Dostoevsky, one of the greatest novelists of all times, had a unique ability to depict the social and moral conditions of 19th-century Russia, and anticipated with his writings many philosophical and scientific developments, such as existentialism and psychoanalysis. The study of auto- and hetero-biographic reports, as well as of his literary production, suggests that he suffered from epilepsy since his mid-20s. Most of his seizures were described as generalized convulsive; however, many features, such as the presence of an 'ecstatic' aura, a pallor preceding the generalization, and especially a postictal dysphasia, point to a dominant (mesio-) temporal lobe origin. Although Dostoevsky in his late years complained of progressive memory impairment, he was able to write with his usual cleverness until the end of his life, when he succumbed to a chronic lung disorder. From an epileptological point of view, this uncommon relatively benign evolution is noteworthy, and it offers an insight to the natural course of this illness. A natural course that is mostly unknown in our times, as the availability of antiepileptic drugs and surgery has biased our knowledge. The relationship between epilepsy and Dostoevsky's production is twofold. Firstly, as he had a tendency towards autobiographical descriptions not only of facts but also of thoughts, his novels represent a valuable source for the understanding of his illness. Secondly, his works contribute greatly to the de-stigmatization of patients with epilepsy.
\end{abstract}

Copyright (C) 2005 S. Karger AG, Basel

'...ma le fotografie chiudono il visibile in un rettangolo. Il visibile senza cornice è sempre un 'altra cosa.'

('...but photographs constrict the visible in a rectangle. The visible without frame is always something else.')

Antonio Tabucchi

Notturno Indiano, 1984 
The work of Dostoevsky, a novelist, journalist and short-story writer, is considered to be one the most impressive, not only among the Russian, but definitely also within the world literature. His powerful and finely tuned depictions of the human condition in all its variety, and his profound philosophical, psychological and religious insights of human nature are characteristic for his style. His novels anticipated and influenced several developments of the 20th-century ways of thinking, including psychoanalysis and existentialism. The writer's own troubled life, combined with a particularly fruitful background, enabled him to reach the sublimation of literary work.

Since his young years, Dostoevsky had recurrent seizures, thus fulfilling the definition of epilepsy. What type of seizures did he suffer from? And what influence did his illness exert upon his literary production?

If a modern Physician would be requested to find an answer to these questions, he would take the history, perform a physical examination of the Patient, order some ancillary tests, then formulate a differential diagnosis and, if necessary, prescribe a treatment. As the Physician is working more than a century after Dostoevsky's death, he only has to deal with 'second-hand' history taking. Furthermore, the irreversible passage of time prevents him from asking his Patient anything.

Our Physician has to keep his objectivity, although his work will be dominated by the 'problem of the frame': he only enjoys a limited view over the reality of the past (fig. 1).

Let's follow him during his attempt.

\section{Personal Medical History}

Fyodor Mihailovich Dostoevsky was born in Moscow in 1821, at the hospital where his father worked as a medical doctor. The Patient was the second of seven siblings [Siegel and Dorn, 2001]. At the age of 7, he had an episode of auditory hallucination (a frightened scream), possibly related to a mysterious upset event that happened in his family [Alajouanine, 1963]. In 1837, his mother died; in the same year, he suffered from some type of 'nervous breakdown' [Vallery-Radot, 1956], and he had a transient aphonia, probably of functional origin [Voskuil, 1983]. Two years thereafter, his father passed away.

After completing his training as naval engineer in St. Petersburg, the Patient began to work for the Ministry of War (1843). During that period, he began to focus on literature. These years were characterized by a difficult financial situation, further complicated by his passion for gambling [Siegel and Dorn, 2001].

According to most sources, the Patient experienced his first epileptic attack, a 'violent seizure' during a funeral, in 1846, possibly after an illness 


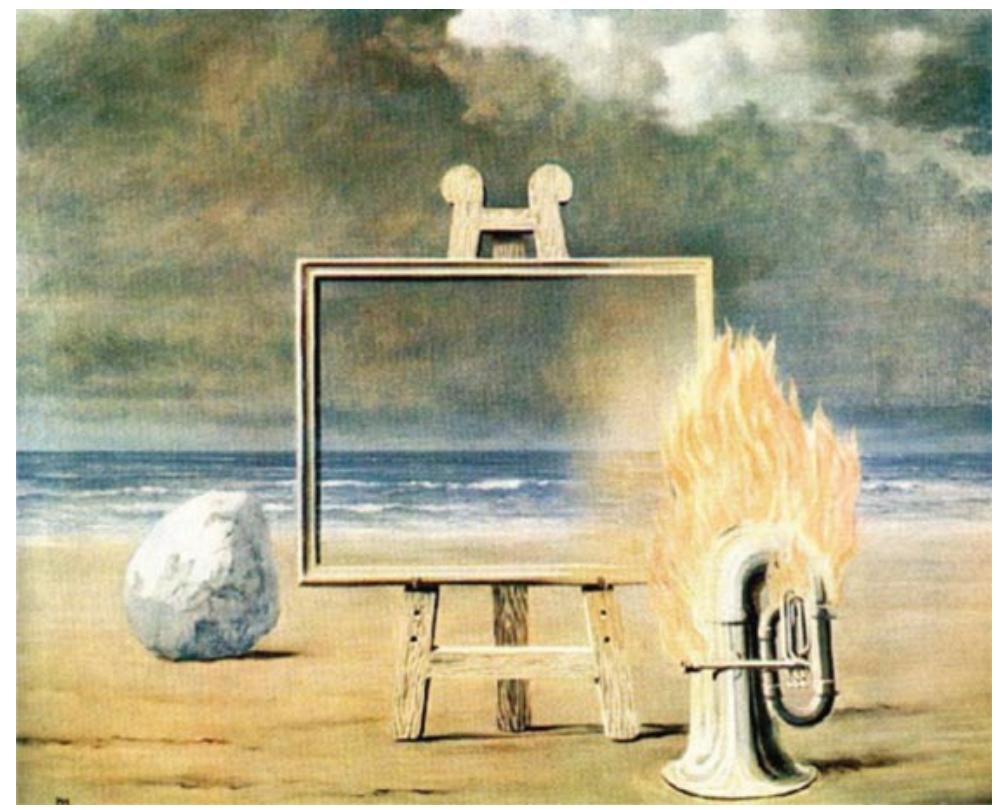

Fig. 1. René Magritte's The Fair Captive exemplifies this problem: only the marina, but not the stone, is seen through the frame. Copyright (C) ProLitteris, 2005, CH-8033 Zürich.

with 'an irritation of the entire nervous system, ... the ailment attacked the heart...' [Voskuil, 1983]. In the same year, at a party, his face 'changed queerly, and a frightened look came into his eyes. A few minutes passed, and then in a hollow voice he asked: "Where am I?".' He went out of the room, but then he was found shaking [Voskuil, 1983]. Dr. Janowsky, a friend of his, described him as 'below medium height, broad boned...' (fig. 2), with an irregular pulse, and traces of ancient rickets and tuberculosis. This doctor mentioned further generalized attacks, sometimes heralded by an expression of terror [Voskuil, 1983]. In spite of these reports, the seizures of that period have been described as relatively mild [Alajouanine, 1963; Siegel and Dorn, 2001].

In 1849, Dostoevsky was found guilty of conspiracy with a revolutionary movement. At the beginning of the imprisonment, he wrote that his 'nerves were breaking down' [Vallery-Radot, 1956; Mayer, 1992]. He was sentenced to death, but at the very moment of the execution, the penalty was commuted to deportation to Siberia. This episode will mark our young Patient for his life. Those long years allowed him close contact with people of the most varied social conditions, and thus represented a key experience for his forthcoming literary work [Vallery-Jadot, 1956; Siegel and Dorn, 2001]. During that extremely difficult period he had many generalized convulsions. Although these have been regarded as the beginning of 


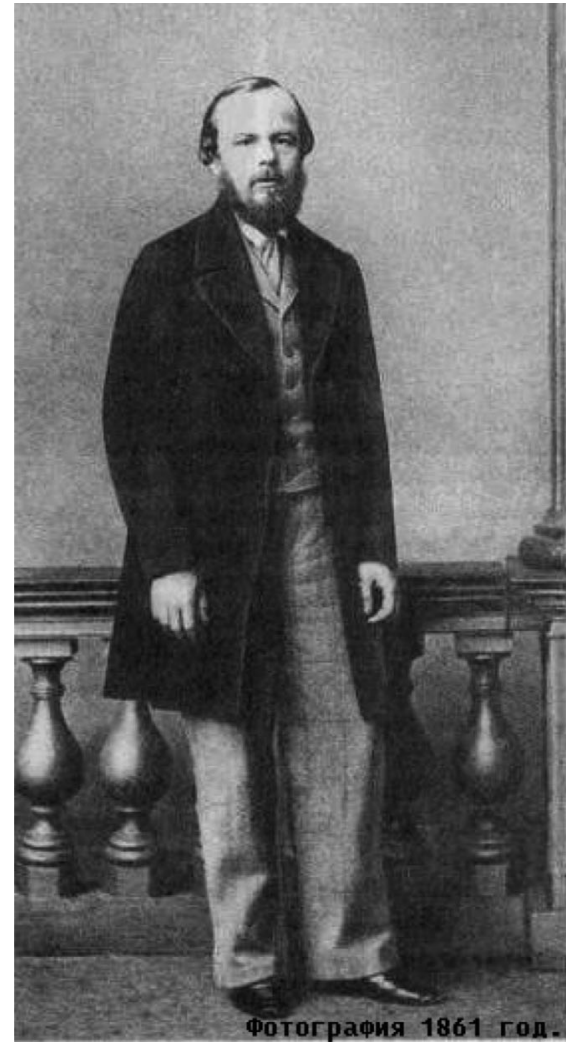

Fig. 2. A rare photograph of F. M. Dostoevsky at the age of 40 . Reproduced with kind permission of Aleksey Astrahantsev, www.dostoevsky.df.ru.

grand-mal seizures [Siegel and Dorn, 2001], they most likely represented an increase in frequency. In a letter to his brother Andrej, he mentioned his recurrent seizures as well as attacks of stabbing headache (1854) [Vallery-Jadot, 1956]. A Military Doctor, Major Ermakov, wrote in 1857 that the Patient had '... a quite weak constitution. In 1850 he experienced his first epileptic seizure, with shouting, memory impairment, muscle twitches, foam on his lips, difficulty of breathing, and rapid pulse. The attack lasted for 15 minutes, followed by the habitual exhaustion. In 1853 he had another attack, and since then, they recur regularly at the end of each month...' [Voskuil, 1983; Siegel and Dorn, 2001]. At the end of his prison sentence, still in Siberia, he married Maria Isayeva in 1856. During their honeymoon, he had two generalized seizures, probably triggered by sleep deprivation and champagne; he was told for the first time that he suffered from epilepsy [Voskuil, 1983]. At that time, he recognized that his recurring epileptic attacks 'cloud my memory ... I fear they are leading me to dementia...' [Vallery-Jadot, 1956]. Although the Patient experienced most of his seizures during the night breaking his sleep [Gastaut, 1978], several were witnessed when he was awake. 
One of his intimate friends, Strakhov, described: '...normally the attacks came once a month, sometimes more often ...I experienced one of his attacks, I think, in $1865 \ldots$ we had a lively talk, ... he began to be agitated, ... excited...he opened his mouth to say something, I looked at him with close attention. Suddenly a strange, long, aimless scream came out of his open mouth and he fell to the floor, unconscious... his body twitched and his mouth became foamy... Dostoevsky told me that just before the seizures he used to become ecstatic...' [Siegel and Dorn, 2001]. Another friend, Mrs. Kovaleskaya, recalled that Dostoevsky compared his ecstatic aura, a feeling of absolute harmony and happiness, to Mahomet's vision of Paradise: 'I don't know if this felicity lasts for seconds, hours or months, but ... for all the joys that life may bring I would not exchange this one!' [Alajouanine, 1963]. Prince Myskin (The Idiot) will make a remarkably similar statement. Further descriptions of the aura were related by Baron Wrangel [Voskuin, 1983]. The Patient also reported a sensation of bilateral twitching and 'itching in the hands' at the beginning [Gastaut, 1984; Siegel and Dorn, 2001], and speech impairment after the seizures: 'It was a long time before I could speak', and 'When writing, I still made mistakes with the words' [Alajouanine, 1963]. His first wife wrote about another seizure: '.. suddenly he turned pale, lurched on the divan and began to lean over to my side...suddenly came a fearful cry...', followed by convulsions and postictal confusion [Voskuil, 1983].

After having resumed his artistic activity, the Patient was allowed to come back to St. Petersburg in 1859. As our Physician has noticed, the frequency of his seizures clearly worsened during and after his Siberian period [Alajouanine, 1963; Siegel and Dorn, 2001].

In 1862, Dostoevsky undertook his first journey across Europe; during those weeks he discovered the 'corrupted' nature of Western Europeans, leading to a reappraisal of the 'Russian spirit'. He began a second trip to Western Europe in 1863, where his gambling mania abruptly (but transiently) ended the relationship with his beloved Apolinarya Suslova. The following year brought two tragedies: the death of his wife (tuberculosis) and of his beloved brother Mikhail. Later, a third European journey ended again with a clash with Mrs. Suslova [Siegel and Dorn, 2001].

Forced into it by his financial situation, Dostoevsky accepted a tough editorial contract, compelling him to write a novel in a very short time. The stenographer Anna Snitkina helped him finish the work (The Gambler), which shares with many other novels a strong autobiographic trait. She married him at the beginning of 1867. A new peregrination through Europe was initiated shortly thereafter. In Basel he saw the Holbein painting of the Deposition, which will be mystically depicted in The Idiot: his wife wrote that in the museum he got a 'scared expression on his face, as I saw so often during the first minute of his 
epileptic attacks', but fortunately it did not end up with a generalization [Schischkin, 2003]. However, in Geneva he experienced a prolonged convulsion as his wife started to go into labor, followed by a long postictal period [Mayer, 1992; Schischkin 2003]. His beloved daughter Sonja was born safely shortly thereafter, but she died tragically at the age of 3 months of an acute illness [Mayer, 1992].

Back to Russia, Dostoevsky was experiencing the exacerbating effects of stress on his seizures [Voskuil, 1983]. He published two masterpieces: The Idiot and The Possessed. Thereafter, he continued to write regularly, even if during his 50 s he began to suffer from increasing breathing difficulties [Siegel and Dorn, 2001], for which the Patient underwent several cures in Bad Ems [Voskuin, 1983]. It seems that then his seizures tended to recur less often [Voskuin, 1983; Siegel and Dorn, 2001]; however, he complained in 1870, after one episode that: ' ...it is four days now, and my head is still not fresh...impossible to think or to work' [Gastaut, 1978], as well as of psychic depression lasting several days [Voskuin, 1983]. Noteworthy, he also reported significant memory impairment [Voskuin, 1983]. In his last years he used to take opium solutions, but this apparently was not intended to cure his epilepsy, for which, besides some bloodletting by Dr. Janowsky, he did not receive any specific treatment [Voskuin, 1983].

One year after completion of his last great work, The Brothers Karamazov (1880), he succumbed to his lung disorder, probably emphysema or tuberculosis [Mayer, 1992; Siegel and Dorn, 2001]. Remarkably, his epileptic seizures did not play a role in the etiology of his death.

\section{Family History}

The father had a tendency towards alcoholism, as did many members of his family, and he was described as a severe, pedantic, and stingy man. Early reports claimed that he was murdered by his servants [Vallery-Radot, 1956]. However, newer interpretations point to a hemorrhagic stroke [Voskuil, 1983]. The mother died of tuberculosis [Siegel and Dorn, 2001]. One of his sons died in status epilepticus during an acute illness at the age of three [Siegel and Dorn, 2001].

\section{Physical Examination}

Apart from the vague descriptions by Drs. Janowsky and Ermakow, our Physician did not find any pertinent medical records. 


\section{Complementary Examinations}

Due to an insurmountable chronological problem, the Patient was unfortunately not able to show up at the right time for the scheduled EEG and MRI, or to have a blood screening.

\section{Discussion}

Our Physician will summarize the facts.

In contrast to Gastaut [1978], he does not find any evidence of a family history of epilepsy. In particular, the fatal status epilepticus of Dostoevsky's son was most likely symptomatic of an infectious illness [Voskuil, 1983]. The Physician also assumes that the birth and early development of the Patient were normal. The episode of verbal hallucination during childhood has been thought to represent the first partial seizure [Vallery-Radot, 1956]; however, our Physician tends to downplay it, as this appears to be isolated, and the Patient never reported acoustic sensations before his convulsions.

In his early years, Dostoevsky's transient aphonia and 'nervous breakdowns' suggest a neurotic trait [Voskuil, 1983], although the possibility of some ill-defined auras (simple partial seizures) cannot be ruled out with certainty. These elements, together with his putative animosity towards his father, induced Freud to interpret the parricide of The Brothers Karamazov as expression of an Oedipus complex; furthermore, the Austrian psychoanalyst regarded his seizures as psychogenic, since Dostoevsky was thought to have experienced his first convulsion at the moment when he was told of his father's death [Gastaut, 1978; Siegel and Dorn, 2001].

Our Physician's sources, nevertheless, clearly describe that the first documented seizure occurred in 1846 , at the age of 25 , thus 7 years after that episode. Several descriptions by his friends and relatives leave no doubt that Dostoevsky had 'organic' generalized seizures, with tachycardia, jerking of all extremities, long postictal periods, and triggering by stress, alcohol and sleep deprivation. This semiology, the notion of epilepsy of Dostoevsky's son (as we have seen, probably an incorrect assumption), the nocturnal occurrence of most episodes, the preceding bilateral twitches, the absence of a major psychiatric or neurological disease, and the questioning about the real existence of the ecstatic aura, led Gastaut [1978] to postulate an idiopathic generalized epilepsy (IGE), as 'petit-mal - grand-mal'.

However, other data need to be carefully evaluated.

Our Physician points to the fact that although arrest of speech and of activity may be seen in absences, they are well known in partial complex seizures. 
Furthermore, nocturnal seizures are characteristic not only of IGE or frontal lobe epilepsy, but are also reported in temporal lobe epilepsy (TLE) [Bernasconi et al., 1998]. The postictal depression described by the Patient is interesting: this may be interpreted as a Todd's phenomenon [Stagno, 2001], but even if studies in stroke patients suggest a lateralization towards the (damaged) dominant hemisphere [Carota et al., 2001], the localizing value in epileptic patients is unclear. Headache is not localizing [So, 2001], apart from childhood benign epilepsy, and it is unclear whether the Patient suffered from peri-ictal or interictal pain; in the latter case, a migraine (which is somewhat linked to epilepsy), or a more common tension headache might be postulated. Dostoevsky's 'peculiar' ecstatic aura, although far less frequent than feelings of fear, has been convincingly described in patients with partial epilepsy [Cirignotta et al., 1980], and is thought to be encountered in about $2 \%$ of patients undergoing presurgical workup; it points to a mesiotemporal origin, is non-lateralizing [Stefan et al., 2004], and may suggest amygdalar involvement. It remains unclear whether the patient also experienced frightening auras, as a facial expression of 'fear' could simply reflect astonishment during the ecstatic feeling. Tingling over the midline or the entire body is recognized as a prodrome of TLE [Wieser, 2004], as generalized tremor [Gastaut, 1984], and autonomic dysfunction [Voskuil, 1983; Wieser, 2004], the latter possibly involving spread to the insula. The postictal aphasia represents the most important localizing feature, pointing towards the frontotemporal dominant hemisphere [Wieser, 2004]. Dostoevsky's complaints of worsening memory are well compatible with a chronic TLE, especially after 30 years of illness [Wieser, 2004]; his higher level of intelligence and education probably account for the fact that this aspect did not impair the Patient to the point of hindering his literary activity [Oyegbile et al., 2004]. Finally, one issue is clear for our Physician: the natural history of TLE is basically unknown, since this disorder (especially in association with hippocampal sclerosis) has been described only in the era of antiepileptic treatments. However, 'benign' courses clearly exist [Wieser, 2004], as is suggested by an increasing, but then decreasing seizure frequency throughout the life of Dostoevsky. Our Physician is also thinking of the fact that the Patient did not seem to suffer from hyposexuality, a relatively common issue in (treated) patients with TLE [Gastaut, 1984].

Dostoevsky was an excellent observer not only of his surrounding word, but also of himself. In his works he depicted his experiences, thoughts, beliefs, as well as his illness. As our Physician believes that the Patient is talking to us through his novels, his literary descriptions may further help to understand his disorder.

There are six epileptic characters in his novels [Siegel and Dorn, 2001]. The most famous is Prince Myskin, The Idiot (1868), considered the interpreter 
of Dostoevsky's thoughts [Alajouanine, 1963]. As his 'inventor', he has ecstatic auras, and in the middle of the novel (part 2, chap. 5) possibly a long-lasting twilight state, characterized by a sort of 'forced thinking', as he recurrently feels a particular unpleasant thought, which precedes a (saving) generalized seizure. Forced thinking may be related to auras arising from the dominant frontal or temporal lobe, the former associated with a more verbal, the latter, as in Myskin, with a more emotional feeling [Mendez et al., 1996].

In the early work, The Lodging Woman (1847) the old Murin, an evil person, in whom the seizure inducing property of alcohol consumption is described, has an attack at the very moment he's attempting to murder Ordynov, an artist experiencing ecstatic feelings. This suggests that the patient already had those auras at the beginning of his illness. In The Insulted and Injured (1861), Dostoevsky describes in detail a generalized seizure and the postictal period of the peaceful girl Nelly. In The Possessed (1872) Kirillov, an atheistic mystic, also experiences ecstatic prodromes. Finally, in The Brothers Karamazov, Sverdyakov, the parricide, suffers from epilepsy, he constructs his alibi mimicking a status epilepticus, but his seizures worsen after the murder, and, seeing the Devil in his hallucinations, he hangs himself.

\section{Conclusion}

What type of seizures, respectively of epilepsy, did Dostoevsky suffer from? And how did his illness act on his literary production?

The Patient's disorder has been analyzed by several prominent epileptologists, before our Physician. Some concluded that Dostoevsky had IGE [Gastaut, 1978], but this does not account for the auras and the other ictal and postictal localizing signs. Others suggested a double diagnosis: partial epilepsy coexisting with IGE [Gastaut, 1984]. This combination is very uncommon, occurring in less than $1 \%$ of patients in an epilepsy clinic [Nicolson et al., 2004], and the likelihood for significant cognitive impairment would be greater than with just one sort of epilepsy. A double pathology consisting of epilepsy and 'pseudoseizures' has also been proposed [Dekkers and van Domburg, 2000]. This is surely not rare, and statistically the Patient would have had some chance for this combination. However, although the Patient might have suffered, at least in his young years, from some psychic instability, our Physician does not find positive evidence for non-epileptic seizures in the analyzed material.

Finally, partial epilepsy has been postulated [Voskuil, 1983; Siegel and Dorn, 2001]. Our Physician agrees with this interpretation, as many features of the Patient's history point to a focal onset: the aura, the prolonged twilight state possibly associated with forced thinking, the postictal dysphasia, and the 
progressive memory impairment. Moreover, these elements suggest a dominant temporal lobe origin of the seizures. Thus, our Physician concludes that Dostoevsky probably suffered from TLE (most likely left mesiotemporal), with complex-partial and secondary generalized seizures, with a relatively benign course, possibly triggered by an intercurrent illness in 1846 .

The significance of epilepsy in Dostoevsky's production cannot be emphasized enough. The nature of his auras is likely to have corroborated his mysticism. Besides giving us many detailed descriptions of epileptic characters, he showed that people with epilepsy should not be judged according to their disorder, but according to their nature. And, often, Dostoevsky's epileptics are found to be of pure, noble, and almost 'metaphysic' soul.

With the hope not to having missed too many elements outside of the frame (fig. 1), our Physician wants to conclude underlying that the personality of Dostoevsky and his work may be interpreted, from an epileptological point of view, as:

'.. an extraordinary defense in favor of the countless persons who have been submitted to the unacceptable prejudice that they are destined to intellectual decline because of the repetition of their seizures and of those exceptional epileptic persons whose genius has erroneously been considered as a byproduct of their disease' [Gastaut, 1984].

\section{Acknowledgment}

The authors thank Tracey Milligan, MD, for editorial help.

\section{References}

Alajouanine T: Dostoiewski’s epilepsy. Brain 1963;86:209-218.

Bernasconi A, Andermann F, Cendes F, Dubeau F, Andermann E, Olivier A: Nocturnal temporal lobe epilepsy. Neurology 1998;50:1772-1777.

Carota A, Rossetti AO, Karapanayiotides T, Bogousslavsky J: Catastrophic reaction in acute stroke: A reflex behavior in aphasic patients. Neurology 2001;57:1902-1905.

Cirignotta F, Todesco CV, Lugaresi E: Temporal lobe epilepsy with ecstatic seizures (so-called Dostoevsky epilepsy). Epilepsia 1980;21:705-710.

Dekkers W, van Domburg P: The role of doctor and patient in the construction of the pseudo-epileptic attack disorder. Med Health Care Philos 2000;3:29-38.

Gastaut H: Fyodor Michailovitch Dostoevsky's involuntary contribution to the symptomatology and prognosis of epilepsy. Epilepsia 1978;19:186-201.

Gastaut H: New comments on the epilepsy of Fyodor Dostoevsky. Epilepsia 1984;25:408-411.

Mayer R: Histoire d'un drame: Dostoievski à Genève. Rev Méd Suisse Romande 1992;112:1075-1081.

Mendez M, Cherrier MM, Perryman KM: Epileptic forced thinking from left frontal lesions. Neurology 1996;47:79-83.

Nicolson A, Chadwick DW, Smith DF: The coexistence of idiopathic generalized epilepsy and partial epilepsy. Epilepsia 2004;45:682-685. 
Oyegbile TO, Dow C, Jones J, Bell B, Rutecki P, Sheth R, Seidenberg M, Hermann PB: The nature and course of neuropsychological morbidity in chronic temporal lobe epilepsy. Neurology 2004;62: 1736-1742.

So NK: Epileptic auras; in Wyllie E (ed): The Treatment of Epilepsy, Principles and Practice, ed 3. Philadelphia, Lippincott Williams \& Wilkins, 2001.

Schischkin M: Die russische Schweiz. Ein literarisch-historischer Reiseführer. Zurich, Limmat Verlag, 2003.

Siegel AM, Dorn T: Dostojewskijs Leben im Wechselspiel zwischen Epilepsie und Literatur. Nervenarzt 2001;72:466-474.

Stagno SJ: Psychiatric aspects of epilepsy; in Wyllie E (ed): The Treatment of Epilepsy, Principles and Practice, ed 3. Philadelphia, Lippincott Williams \& Wilkins, 2001.

Stefan H, Schulze-Bonhage A, Pauli E, Platsch G, Quiske A, Buchfelder M, Romstoeck J: Ictal pleasant sensations: cerebral localization and lateralization. Epilepsia 2004;42:35-40.

Vallery-Radot P: Epilepsie et génie. Vingt ans de la vie de Dostoïevski (1837-1857). D’après sa correspondance - Avant et après le bagne. Presse Méd 1956;64:2065-2066.

Voskuil PHA: The epilepsy of Fyodor Michailovitch Dostoevsky (1821-1881). Epilepsia 1983;24: $658-667$.

Wieser HG (compiled from, for the ILAE Commission on Neurosurgery for Epilepsy): Mesial temporal lobe epilepsy with hippocampal sclerosis. Epilepsia 2004;45:695-714.

Andrea O. Rossetti

Epilepsy Unit, Department of Neurology, Brigham and Women's Hospital

75, Francis Street

Boston, MA 02115 (USA)

Tel. +1 617525 7175, Fax +1 617278 6963, E-Mail arossetti@partners.org 